\title{
Стенд для дослідження розширювальних турбомашин малої потужності та агрегатів на їх основі
}

\author{
С. М. Ванєєв, Д. В. Мірошниченко, В. О. Журба, Я. В. Знаменщиков, В. М. Бага, Т. С. Родимченко \\ Сумський державний університет, вул. Римського-Корсакова, 2, м. Суми, 40000, Україна
}

\begin{abstract}
В даний час для вирішення проблем енергозбереження проводяться роботи з дослідження та використання малопотужних розширювальних машин для утилізаційних турбогенераторів. Перспективним $\epsilon$ створення турбоагрегатів на базі відносно тихохідних вихрових розширювальних машин, але робіт по їх експериментальним дослідженням відомо мало. У зв'язку з ичм необхідно створення матеріально-технічної бази, щзо включає нові і модернізовані стенди, експериментальні модельні та натурні установки, об'єкти дослідження, виробниче та технологічне обладнання, обчислювальні і програмні комплекси. У статті представлені результати розробки і тестування елементів стенду досліджень турбогенераторів малої потужності для утилізації енергії стиснутих газів. Створено експериментальний стенд, на якому можна проводити дослідження $і$ випробування розширювальних турбомашин і турбогенераторів на їх основі різного конструктивного виконання потужності до 15 кВт, а також демонструвати роботу турбогенератора потенційним замовникам продукиї. Прилади та обладнання стенду дозволяють плавно змінювати електричне навантаження $і$ отримувати необхідні параметри і характеристики розширювальних машин і турбогенераторів. У складі стенду створена інформаційно-вимірювальна система, яка забезпечує контроль стану обладнання; здійснює реєстрацію інформації $i$ обробку даних вимірювань з представленням результатів в табличному і графічному вигляді; забезпечує надійне зберігання отриманої інформачії тощя. Створено дослідний зразок енергозберігаючого турбогенератора на основі вихрової розширювальної машини. Конструкиія турбогенератора дозволяє досліджувати вплив основних геометричних параметрів проточної частини на ефективність вихрової розширювальної турбомашини $i$ генератора в цілому. Результати роботи будуть використані для дослідження розширювальних турбомашин і утилізаційних турбогенераторів на їх основі, щуо використовують енергію стиснутого газу.
\end{abstract}

Ключові слова: енергозбереження; турбогенератор; вихрова розширювальна машина; стенд; інформаційновимірювальна система

doi: https://doi.org/10.15673/ret.v55i1.1348

(C) The Author(s) 2019. This article is an open access publication

This work is licensed under the Creative Commons Attribution 4.0 International License (CC BY) http://creativecommons.org/licenses/by/4.0/

\section{1. Вступ}

Широке впровадження турбоустановок в якості автономних джерел енергії вимагає широких всебічних теоретичних і експериментальних досліджень і випробувань модельних і натурних розширювальних турбомашин та турбогенераторів в цілому. Для виконання таких досліджень необхідно створення матеріальнотехнічної бази, що включає нові і модернізовані стенди, експериментальні модельні та натурні установки, об'єкти дослідження, виробниче та технологічне обладнання, обчислювальні і програмні комплекси. Необхідно розробити комплекс методик та програм проведення і обробки результатів експериментальних модельних досліджень і натурних випробувань, що дозволить отримати достовірні характеристики розширювальних турбомашин, інших елементів турбогенераторів та турбогенераторів в цілому. Отримані дослідні характеристики повинні підтвердити правочинність і достовірність розроблених принципів проектування розширювальних турбомашин і утилізаційних турбогенераторів на їх основі, що використовують енергію стиснутого газу.
В даний час для утилізації енергії стиснутих газів пропонується використовувати високообертові (до 100000 об/хв), часто парціальні, осьові і радіальні розширювальні машини [1]. Відомі турбоагрегати малої потужності на базі струминно-реактивних турбін [2-4] прості конструктивно, але також мають високу оптимальну частоту обертання ротора. Інтерес до вихрових розширювальних машин виникає в зв'язку з тим, що для малих потужностей (до 500 кВТ) вихрові розширювальні машини за багатьма своїми техніко-економічними характеристиками перевершують всі інші типи. Вихрові розширювальні машини, як і об'ємні, здатні спрацьовувати великі перепади тиску і мають великі відношення пускового моменту до номінального. Однак вихрова турбомашина не має робочих поверхонь, що труться, не забруднює робоче середовище і забезпечує найкращі показники ресурсу і надійності. У порівнянні з розширювальними машинами динамічної дії вихрові мають швидкість обертання в 5..10 разів менше, що дозволяє використовувати в якості опор підшипники кочення i виключити з систем проміжні редуктори. Схеми розрахунку вихрових машин, які в даний час використову- 
ють, включають в себе коефіцієнти, визначені експериментальним шляхом. Особливо важливо накопичення експериментального матеріалу в області дослідження вихрових розширювальних машин, так як робіт $[5,6]$ по їх експериментальним дослідженням відомо мало.

\section{2. Завдання випробувань}

Завдання випробувань: отримання достовірних характеристик вихрової розширювальної машини i турбогенератора на іiі основі; визначення впливу режимних i геометричних параметрів на економічність i характеристики вихрової розширювальної турбомашини i турбогенератора на іiі основі на номінальному i змінних режимах; отримання коефіцієнтів для уточнення методик розрахунку вихрової розширювальної турбомашини і турбогенератора на іiї основі.

\section{3. Опис стенду}

На кафедрі технічної теплофізики СумДУ створений стенд, який дозволяє проводити випробування дослідних зразків турбогенераторів на основі різних розширювальних машин та різних типів генераторів малої потужності до 15 кВт.

Створені також дослідний зразок турбогенератора на основі вихрової розширювальної машини потужністю 11 кВт (рисунок 1) та дослідний зразок турбогенератора на основі струминно-реактивної розширювальної машини потужністю 1,5 кВт (рисунок 2).

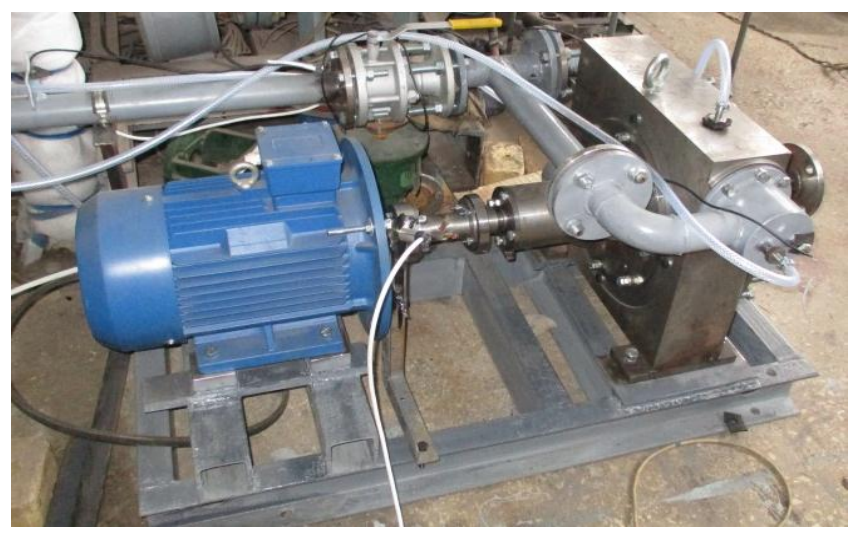

Рисунок 1 - Турбогенератор на основі вихрової розширювальної машини

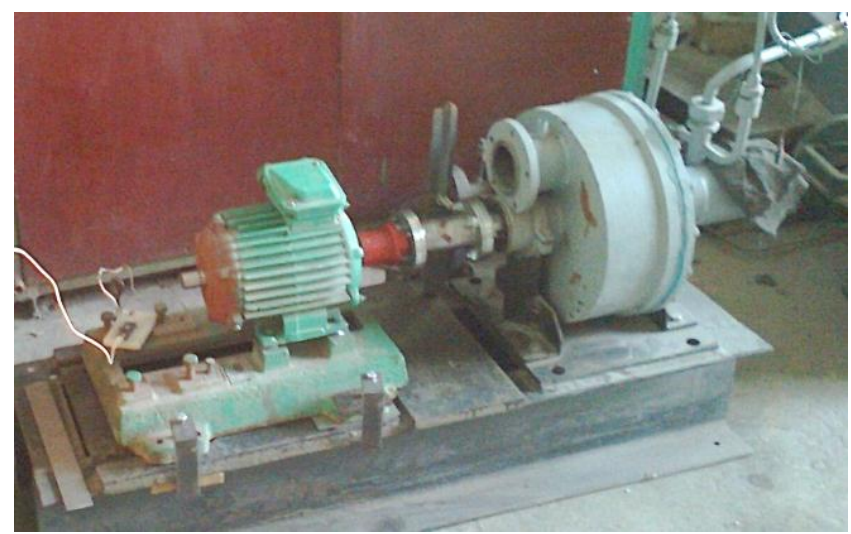

Рисунок 2 - Турбогенератор на основі струминнореактивної розширювальної машини.

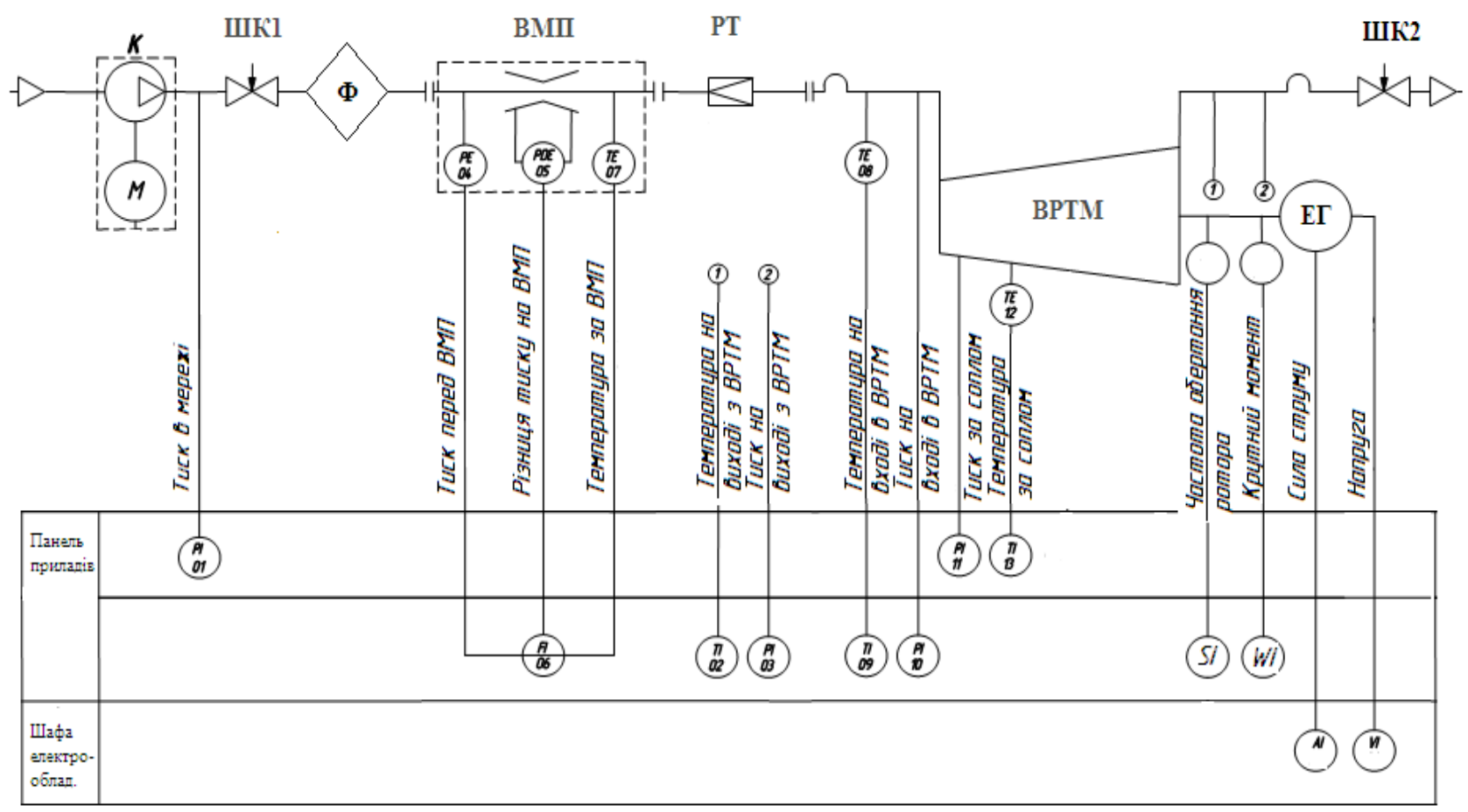

К - компресор; ВРТМ - вихрова розиирювальна турбомашина; ЕГ - електрогенератор; РТ - регулятор тиску; ШК - шаровий кран; ВМП - витратомірний пристрій; Ф - фільтр; FI - блок індикацї витратоміра; PI - манометр; ТI - термометр; SI - блок тахометра; WI - блок індикації крутного моменту.

Рисунок 3 - Схема стенда (принциипова) 
Турбогенератор призначений для перетворення потенційної енергії стиснутого газу спочатку в механічну енергію на валу за допомогою вихрової або струминно-реактивної розширювальної турбомашини, а потім механічної енергії в електроенергію за допомогою електрогенератора.

В процесі випробувань вихрової розширювальної турбомашини і турбогенератора на іiї основі передбачено регулювання:

а) кута входу потоку газу, що витікає з сопла, на лопатки робочого колеса (кута між віссю сопла і дотичній до зовнішнього діаметру робочого колеса);

б) діаметра сопла, що дозволяє змінювати витрату і швидкості на виході з сопла, а також - відношення площі сопла до площі меридіонального перерізу проточної частини, за рахунок чого можливе підкручення потоку на вхідній ділянці проточної частини; в) частоти обертання робочого колеса для визначення оптимальних, 3 точки зору гідравлічного ККД, значень наведеної колової швидкості.

Принципова схема та фото стенду представлені на рисунку 3 та рисунку 4 відповідно.

Основними складовими стенду є:

- джерело стиснутого повітря (компресор) рисунки 3, 4;

- трубопровідна обв'язка стенду, а також арматура запирання і регулювання тиску газу рисунки 3,4 ;

- турбогенератор, який складається 3 розширювальної турбомашини і електрогенератора рисунки 1, 2, 3, 4;

- система силового підключення, контролю та регулювання електроенергії, що виробляється рисунки 4, 5;

- інформаційно-вимірювальна система (IBC) для вимірювання витрати робочого тіла, крутного моменту на валу, частоти обертання ротора, тисків і температур на вході и виході розширювальної машини (рисунок 8).

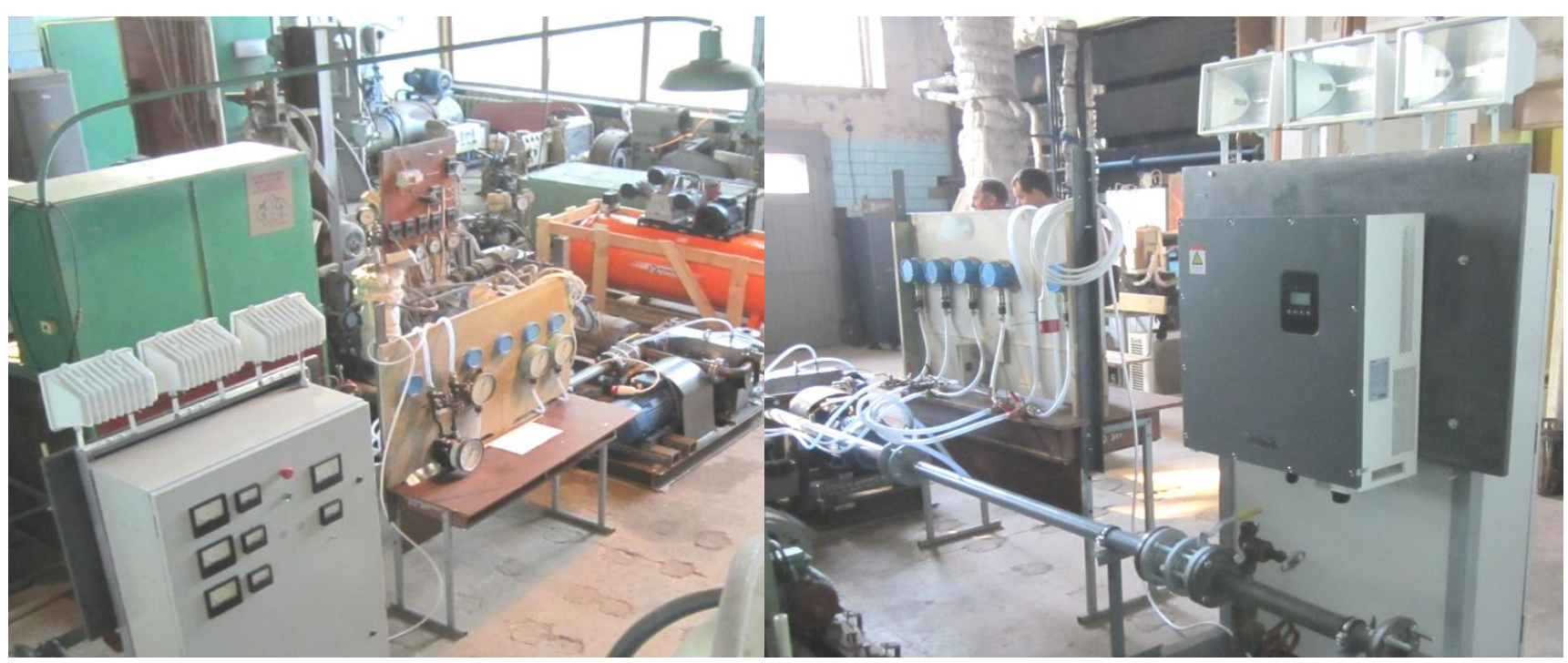

Рисунок 4 - Фото стенда

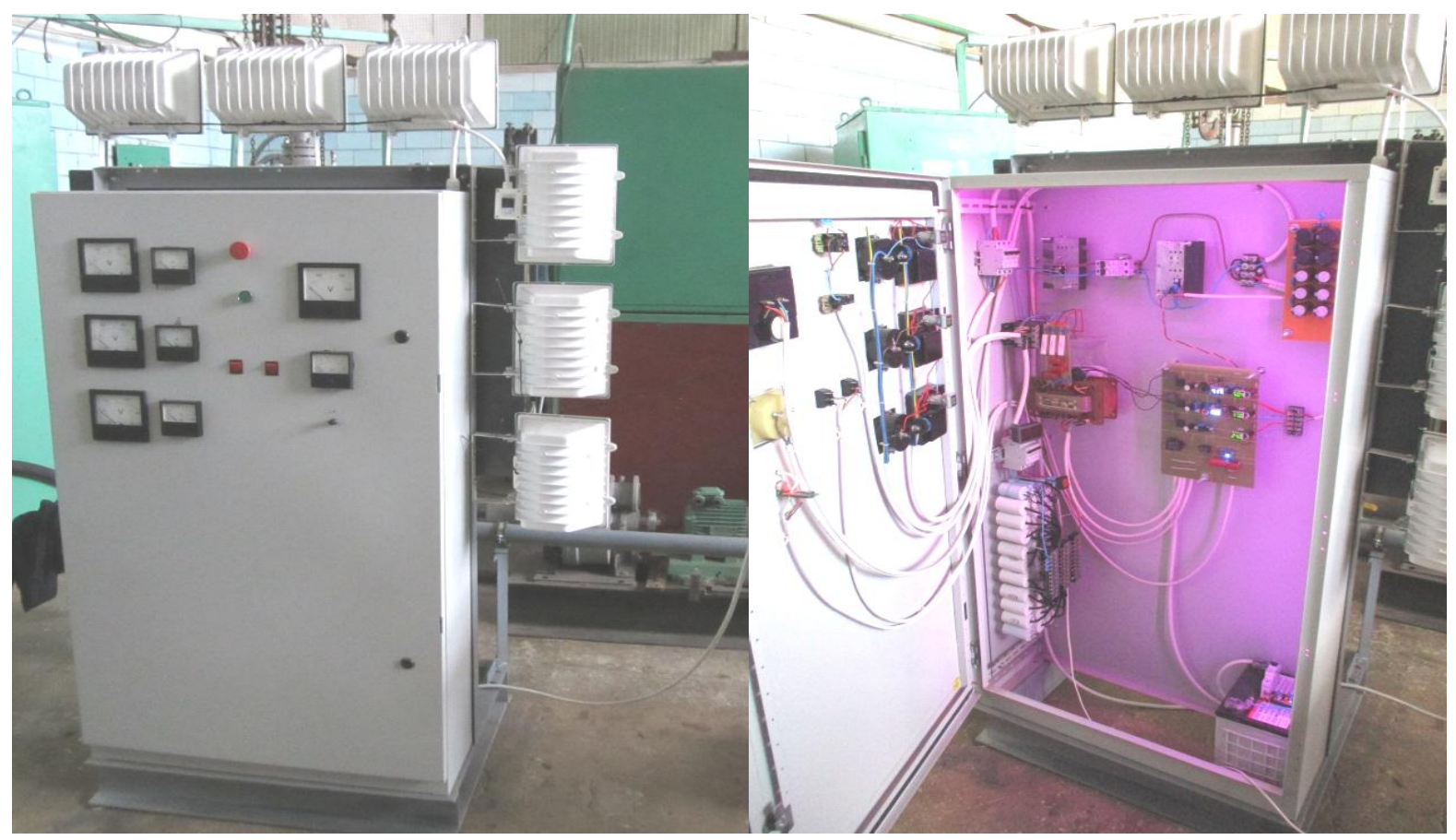

Рисунок 5 - Система силового підключення, контролю та регулювання електроенергї, щзо виробляється 
Елементи системи силового підключення, контролю та регулювання електроенергії, що виробляється, змонтовані в шафі та на рамі окремим модулем стенду (рисунки 4, 5). Конструкція стенду дозволяє легко приєднувати до розширювальної машини різні моделі та типи генераторів, як синхронного так і асинхронного принципу дії, для відпрацювання та дослідження турбогенераторів.

В цьому модулі стенду реалізовані дві схеми електричного навантаження (рисунки 6, 7) та можливість перемикання 3 однієї схеми на іншу. Функціональна схема електричного навантаження турбогенератора 3 синхронним генератором показана на рисунку 6, а 3 асинхронним генератором - на рисунку 7.

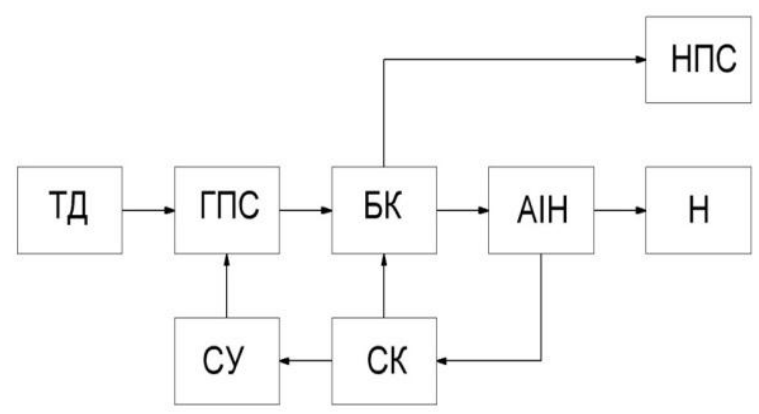

ТД - турбодетандер (вихрова розширювальна турбомашина); ГПС - генератор постійного струму (синхронний генератор); БК - блок керування ГПС; СК система керування вихідними параметрами турбогенератора; СУ - система контролю вихідної напруги ГПС; АІН - автономний інвертор напруги; НПС - навантаження постійного струму; $\mathrm{H}$ - навантаження змінного струму.

Рисунок 6 - Функціональна схема електричного навантаження турбогенератора з синхонним генератором

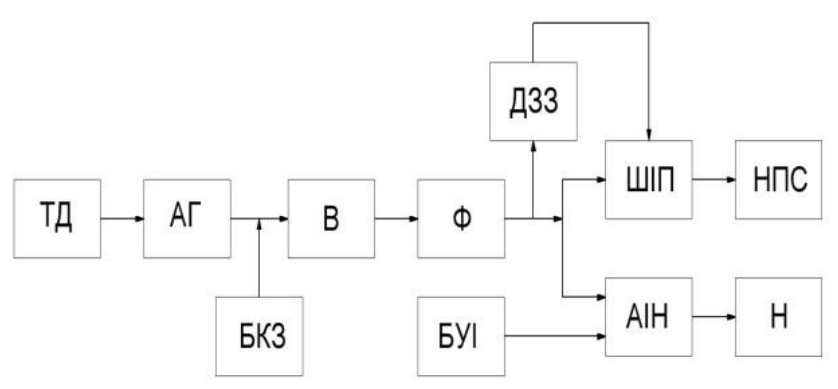

ТД - турбодетандер (вихрова розиирювальна турбомашина); АГ - асинхронний генератор; БКЗ - блок самозбудження; В - випрямляч; Ф - ємнісний фільтр; ШІП - ииротно-імпульсний перетворювач; ДЗЗ - датчик зворотного зв'язку по напрузі; БУІ - блок управління інвертором; АІН - автономний інвертор напруги; НПС - навантаження постійного струму; $\mathrm{H}$ - навантаження змінного струму.

Рисунок 7 - Функиіональна схема електричного навантаження турбогенератора з асинхронним генератором

У вихровій розширювальній турбомашині енергія надлишкового тиску стиснутого газу перетворюється в механічну енергію на валу машини. В синхронному генераторі механічна енергія перетворюється в електричну енергію постійного струму. За допомогою блока керування і системи контролю вихідної напруги синхронного генератора, а також системи керування вихідними параметрами турбогенератора маємо на виході генератора струм необхідних параметрів. Автономний інвертор напруги перетворює постійну напругу в змінну напругу необхідного значення і форми. В системі передбачені навантаження постійного струму і навантаження змінного струму.

У порівнянні зі схемою, наведеною на рисунку 6, при наявності в системі асинхронної електричної машини для роботи іiі в генераторному режимі, необхідно мати блок самозбудження, що забезпечує самозбудження АГ при відсутності додаткових джерел електроживлення (рисунок 7), а також стійкий режим роботи АГ (на основі блока конденсаторів). В систему входить також блок випрямлячів, що перетворює трифазну змінну напругу в постійну і ємнісний фільтр, що згладжує пульсації випрямленої напруги. Широтноімпульсний перетворювач автоматично регулює навантаження АГ, підтримуючи стабільність випрямленої напруги за допомогою датчика зворотного зв'язку по напрузі.

Для живлення мікроконтролерів та датчиків системи силового підключення, контролю та регулювання електроенергії використовується акумулятор 3 зарядним пристроєм та трансформатор напруги. Для реєстрації та контролю напруги та сили струму, що протікає, в різних частинах схем застосовуються амперметри та вольтметри змінного або постійного струму (рисунок 5). В якості навантаження використовуються галогенові прожектори потужністю до 1000 Вт кожен (рисунки 4,5 ) та повітряні ТЕНи потужністю до 2 кВт.

Розроблена система силового підключення, контролю та регулювання електроенергії, що виробляється, дозволяє підтримувати задану (необхідну) вихідну напругу та потужність при фіксованій частоті змінного струму різних типів та моделей генераторів.

\section{4. Інформаційно-вимірювальна система стенду}

Для отримання вимірювальної інформації про параметри вихровий розширювальної турбомашини, іiі перетворення і обробки у складі стенду створена інформаційно-вимірювальна система (IBC) (рисунок 8), яка дозволяє:

- забезпечувати контроль стану обладнання (для візуального контролю стану обладнання в складі IBC $\epsilon$ мнемосхема (рисунок 9), яка в реальному масштабі часу регіструє та відображає поточні параметри елементів стенду в процесі випробувань);

- здійснювати реєстрацію інформації і обробку даних вимірювань за допомогою створеного авторами спеціального програмного забезпечення, що надходять від датчиків в процесі випробувань і роботи IBC;

- забезпечувати надійне зберігання отриманої інформації;

- представляти результати вимірювань в табличному і графічному вигляді;

- реєструвати швидкозмінні процеси, що виникають при знятті характеристик. 


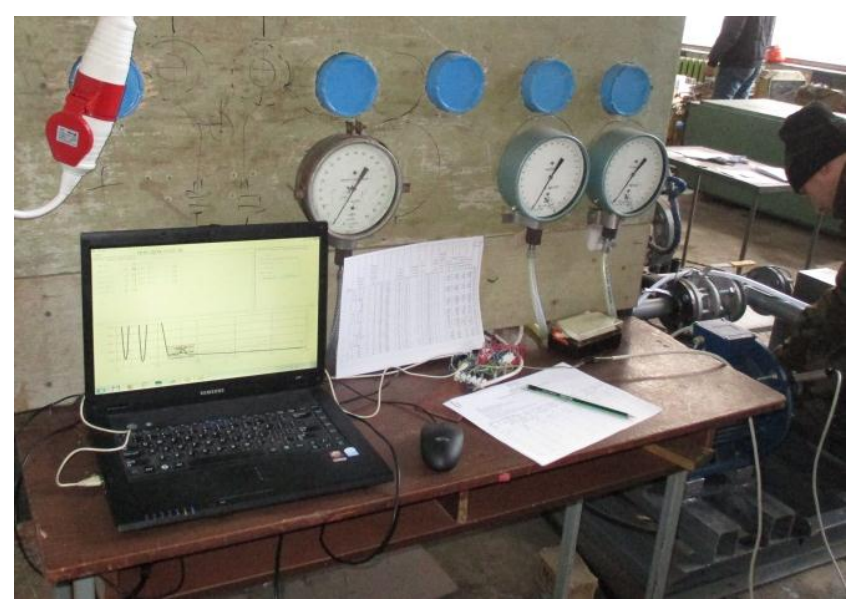

Рисунок 8 - Зовнішній вигляд елементів IBC

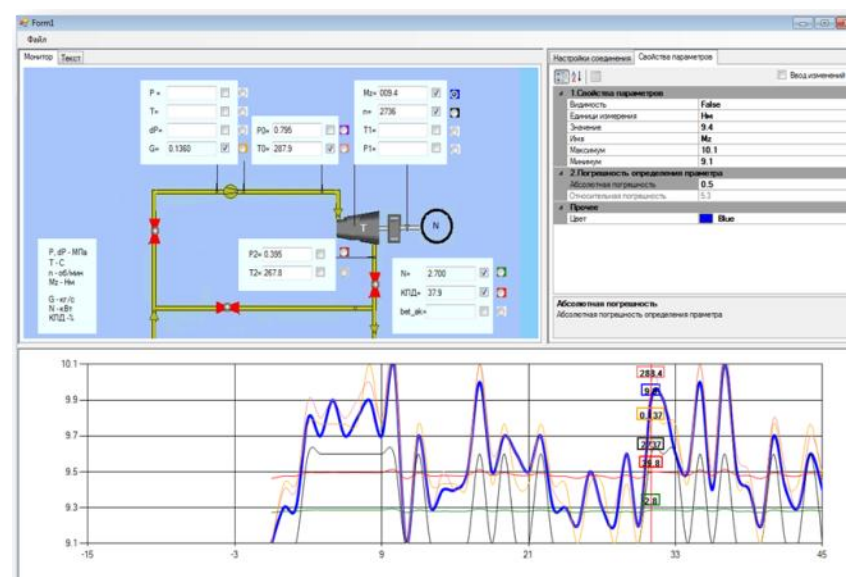

Рисунок 9 - Інтерфейс програми для контролю IBC

Для забезпечення вказаних вище можливостей стенд оснащений датчиками для виміру статичних тисків, температур, частоти обертання і крутного моменту.

IBC має 5 каналів тиску (оснащених датчиками типу “Сапфир-22") для перетворення тиску в електричний сигнал 4-20 мА, що подається в перетворювач аналогових сигналів в цифровий, який обробляється комп'ютером. $\mathcal{E}$ також до 10 температурних каналів для реєстрації температури повітря уздовж повітряного тракту стенду та температури корпусних деталей. Максимальний розмір чутливого елемента датчика DS18B20 не перевищує 5 мм (рисунок 10). Він являє собою мікросхему з мікропроцесором, яка поєднується 3 мережею. Діапазон вимірюваних температур $-55^{\circ} \mathrm{C}-+125^{\circ} \mathrm{C}$, ціна ділення $0,1^{\circ} \mathrm{C}$. Цей прилад має велику точність вимірювання завдяки тому, що сигнал, який виникає у чутливому елементі, одразу ж перетворюється у цифровий код та вже потім передається на вторинний прилад.

Необхідність вимірювання потужності, переданої обертовим валом, призвела до необхідності застосувань пристроїв для вимірювання крутного моменту і частоти обертання валів. Підвищення точності вимірювання потужності на валу дозволяє більш точно визначати ККД розширювальної турбомашини і системи перетворення механічної енергії в електричну, покращує якість експерименту і тим самим дозволяє виявляти вплив малопомітних факторів на економічність. Особливого значення набуває вимірювання потужності на високошвидкісних установках, де в ряді випадків звичайні системи вимірювання або непридатні, або мають невисоку точність.

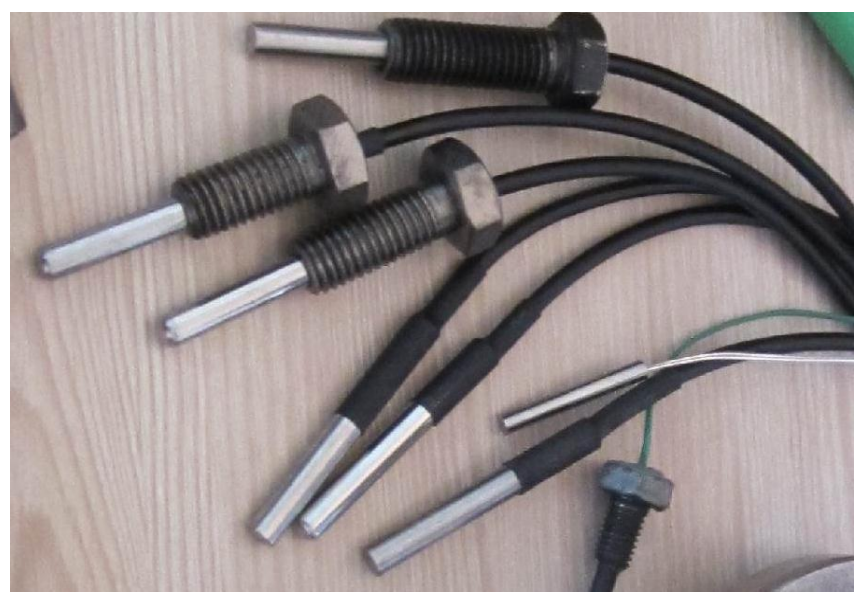

Рисунок 10 - Зовнішній вигляд зондів для вимірювання температур

У системах автоматичного регулювання для визначення крутних моментів застосовуються торсіометричні прилади [7]. В даному стенді для вимірювання крутного моменту, що діє на торсіонний вал, використовується тензометричний метод; для вимірювання частоти обертання валу використовується індукційний датчик.

У створеній IBC передбачені канал вимірювання частоти обертання ротора і канал вимірювання крутного моменту. Для визначення і реєстрації значення крутного моменту створений прилад, який складається 3 торсіона і розміщених в ньому тензорезисторів, мікропроцесорів, wi-fi-передавача i акумулятора. Прилад дозволяе передавати показання бездротовим методом. Прилад було відроблено в динаміці за допомогою високообертової струминно-реактивної розширювальної машини на кафедрі ТТФ СумДУ (рисунок 2). Під час динамічних випробувань прилад вимірював крутний момент при змінній частоті обертання ротору від 500 до 9000 об/хв.

Обробка інформації може здійснюватися комп'ютером, який встановлюється як в операторній стенду, так і в щиті управління стендом. Робота IBC здійснюється в реальному масштабі часу, і після встановлення нового режиму роботи система дозволяє дуже швидко отримувати і обробляти інформацію про випробування (час обробки інформації, що знімається з одного каналу, менше 1 секунди).

\section{5. Висновки}

1. Створено експериментальний стенд, на якому можна проводити дослідження і випробування розширювальних турбомашин і турбогенераторів на їх основі різного конструктивного виконання потужності до 15 кВт, а також демонструвати роботу турбогенератора потенційним замовникам продукції. 
Прилади та обладнання стенду дозволяють плавно змінювати електричне навантаження і отримувати необхідні параметри і характеристики розширювальних машин і турбогенераторів.

У складі стенду створена інформаційновимірювальна система, яка забезпечує контроль стану обладнання; здійснює реєстрацію інформації і обробку даних вимірювань з представленням результатів в табличному і графічному вигляді; забезпечує надійне зберігання отриманої інформації тощо.

Результати досліджень турбогенераторів та їх елементів на стенді можуть використовуватися для проектування малопотужних турбогенераторів та турбоприводів.

2. Створений дослідний зразок енергозберігаючого турбогенератора на основі вихрової розширювальної машини на параметри:

- номінальна потужність на клемах електрогенератора -3 кВт;

- тиск газу на вході - 0,3-0,6МПа (абс);

- тиск газу на виході - 0,1-0,3МПа (абс);

- номінальна частота обертання ротора турбогенератора - 3000 об/хв;

- витрата газу - не більше 500 нм3/год.;

- ККД - не нижче 40\%.

Номінальна потужність на клемах електрогенератора може становити 10 кВт при збільшенні тиску на вході до 0,8 МПа (абс.) і витрати газу до 1500 нм3/год.

Конструкція турбогенератора дозволяє досліджувати вплив основних геометричних параметрів проточної частини на ефективність вихрової розширювальної турбомашини і генератора в цілому.

3. Як показують дослідження найбільш перспективним $\epsilon$ використання вихрових розширювальних турбомашин для створення турбогенераторів і трубопроводів з частотою обертання 3000 об/хв потужністю до 500 кВт:

- у пневмосистемах в якості пневматичного двигуна або пневмостартера;

- у промисловості в якості турбоприводів насосів, вентиляторів, компресорів, а також в якості турбогенераторних агрегатів замість або паралельно 3 вузлами дроселювання парів і газів;

- у промисловій та комунальній теплоенергетиці в котельнях, що мають стандартні котли, де пара часто дроселюється в редукційно-охолоджувальних пристроях до технологічних параметрів, установка турбогенераторних агрегатів дозволить перетворити ці котельні в міні-ТЕЦ і збільшити ефективність використання палива;

- в газотранспортних системах: зокрема, для виробництва електроенергії на газорозподільних станціях, як для власних потреб, так і для віддачі в зовнішню мережу, а також у системах подачі паливного газу в газотурбінні приводи компресорів газоперекачувальних агрегатів.

\section{Література}

1. Фокин, Г.А. Методология создания автономных турбинных источников электрической энергии, использующих энергию сжатого природного газа для собственных нужд газотранспортной системы России: дис. ... д-ра техн. наук : 05.04.02 / Фокин Георгий Анатольевич. $-2015 .-456$ с.

2. Vaneev, S.M. Compressed-air reaction motor and possibilities of its use / S.M. Vaneev, S.K. Korolev, Yu.A. Rukhlov, Yu.T. Fedotov // Chemical and Petroleum Engineering. - 1991. - Vol. 26, Issue 5-6. - P. 304-306

3. Vanyeyev, S. Influence of gap between driving wheel and corps on characteristics of jet-reactive turbine / S. Vanyeyev, A. Berezhnoi // Procedia Engineering. 2012. - Vol. 39. - P. 1-8.

4. Vanyeyev, S. Jet-Reactive Turbine: Experimental Researches and Calculations by Means of Softwares / S. Vanyeyev, V. Getalo // Applied Mechanics and Materials. - 2014. - Volume 630. - P. 66-71.

5. Ванеев, С.М. Разработка и исследование вихревого пневмопривода с внешним периферийным каналом и сопловым аппаратом: дис. ... канд. техн. наук : 05.04.06 / Ванеев Сергей Михайлович. - Москва, 1986. - 183 с.

6. Староверов, К.В. Совершенствование и исследование вихревой машины с периферийным каналом в режиме пневмопривода: дис. ... канд. техн. наук : 05.04.06 / Староверов Константин Владимирович. - Москва, 1990. $-128 \mathrm{c}$.

7. Фролов, Л.Б. Измерение крутящего момента / Фролов Л. Б. - М., «Энергия», 1967. - 120 с.

Отримана в редакції 22.12.2018, прийнята до друку 05.02.2019

\title{
Stand for investigation of low power expansion turbomashines and units on their basis
}

\author{
S. M. Vaneev, D. V. Miroshnichenko, V. O. Zhurba, Ya. V. Znamenshchykov, V. N. Baga, T. S. Rodymchenko
}

Sumy State University, 2, Rymskogo-Korsakova st., Sumy, 40007, Ukraine

\begin{abstract}
At present, work on the research and use of low-power expansion machines for utilizing turbine generators is being carried out to solve energy-saving problems. Creation of turbine units based on simple constructive jet-reactive turbines and relatively slow-moving vortex expansion machines is a promising direction, but work on their experimental research is not well-known. In connection with this, it is necessary to create a material and technical base, which includes new and upgraded stands, experimental model and equipment, research facilities, production and technological equipment, computing and software systems. The article presents the results of the creation of an experimental stand on which it is possible to carry out research and testing of expansion turbomachines and turbogenerators based on their various constructional capacities up to $15 \mathrm{~kW}$, as well as to demonstrate the work of the turbogenerator. A system of power connection, control and regulation of the produced electric power is developed and created, which allows to
\end{abstract}


maintain a given output voltage and power at a fixed frequency of alternating current of different types and models of generators. The devices and equipment of the stand allow to smoothly change the electric load and receive the necessary parameters and characteristics of turbine generators. The information-measuring system is created in the stand, which provides the control of the state of the equipment; carries out the registration of information and processing of measurement data with the presentation of results in tabular and graphical form. To determine and register the value of torque, an instrument has been created that allows you to transmit the readings wirelessly. The device was used at variable speed of rotor from 500 to $9000 \mathrm{rpm}$. The results of research on turbine generators and their elements on the stand can be used for the design of low-power turbine generators and turbine drives.

Keywords: Energysaving; Turbogenerator; Vortex expansion machine; Stand; Information and measurement system.

\section{References}

1. Fokin, G.A. (2015) Metodologiia sozdaniia avtonomnykh turbinnykh istochnikov elektricheskoi energii, ispolzuiuschikh energiiu szhatogo prirodnogo gaza dlia sobstvennykh nuzhd gazotransportnoi sistemy Rossii [Methodology for creating autonomous turbine sources of electrical energy using compressed natural gas for the needs of the Russian gas transmission system], Ph.D. dissertation, Moscow, Russian.

2. Vaneev, S.M., Korolev, S.K., Rukhlov, Yu.A., Fedotov, Yu.T. (1991) Compressed-air reaction motor and possibilities of its use. Chemical and Petroleum Engineering, Volume 26, Issue 5-6, 304-306. doi: https://doi.org/10.1007/bf01156878

3. Vaneev, S., Berezhnoi, A. (2012) Influence of gap between driving wheel and corps on characteristics of jetreactive turbine. Procedia Engineering, Volume 39, 1-8. doi: https://doi.org/10.1016/j.proeng.2012.07.001

4. Vaneev, S., Getalo, V. (2014) Jet-Reactive Turbine: Experimental Researches and Calculations by Means of Soft- wares. Applied Mechanics and Materials, Vol. 630, 66-71. doi: https://doi.org/10.4028/www.scientific.net/amm.630.66 5. Vaneev, S.M. (1986) Razrabotka i issledovanie vikhrevogo pnevmoprivoda s vneshnim periferiinym kanalom i soplovym apparatom [Development and research of a pneumatic drive with an external peripheral channel and nozzle device], Abstract of Ph.D. dissertation, Moscow, SSSR.

6. Staroverov, K.V. (1990) Sovershenstvovanie i issledovanie vihrevoy mashinyi $\mathrm{s}$ periferiynyim kanalom $\mathrm{v}$ rezhime pnevmoprivoda [Improvement and research of vortex machine with a peripheral channel in pneumatic drive mode], Abstract of Ph.D. dissertation, Moscow, SSSR.

7. Frolov, L.B. (1967) Izmerenie krutiashchego momenta [Torque measurement], Moscow, Energiia, 120 p.

Received 22 December 2018 Approved 05 February 2019 Available in Internet 03 March 2019 